\title{
Potential impact of biocide adaptation on selection of antibiotic resistance in bacterial isolates
}

\author{
Engy Elekhnawy ${ }^{*}$ (D), Fatma Sonbol, Ahmed Abdelaziz and Tarek Elbanna
}

\begin{abstract}
Background: Antibiotic resistance in pathogenic bacterial isolates has increased worldwide leading to treatment failures.

Main body: Many concerns are being raised about the usage of biocidal products (including disinfectants, antiseptics, and preservatives) as a vital factor that contributes to the risk of development of antimicrobial resistance which has many environmental and economic impacts.

Conclusion: Consequently, it is important to recognize the different types of currently used biocides, their mechanisms of action, and their potential impact to develop cross-resistance and co-resistance to various antibiotics. The use of biocides in medical or industrial purposes should be monitored and regulated. In addition, new agents with biocidal activity should be investigated from new sources like phytochemicals in order to decrease the emergence of resistance among bacterial isolates.
\end{abstract}

Keywords: Antibiotics, Biocides, Cross-resistance, Co-resistance, Efflux

\section{Background}

Disinfectants, antiseptics, and preservatives are chemical compounds having the capacity to kill or inhibit the growth of microorganisms. They have a main role in the medical and healthcare settings. In addition, they are extensively used in livestock, paints and coatings, plastics, food and beverage manufacture, pharmaceutical industry, textiles, and consumer products [1]. The term biocide is used to describe this group of chemical compounds.

Disinfection is defined as the process of removing microorganisms from the surfaces of non-living objects. Antisepsis is defined as killing or inhibition of microorganisms that are present on living tissues to limit or prevent the harmful results of infection. Preservatives are included in many pharmaceutical formulations, to prevent microbial spoilage of the product and to reduce the risk to the consumer of acquiring an infection when the

\footnotetext{
* Correspondence: Engy.elekhnawy2020@gmail.com

Pharmaceutical Microbiology, Faculty of Pharmacy, Tanta University, El-Geish Street, Medical Campus, Tanta, El Gharbia Governorate, Egypt
}

preparation is utilized. Preservatives must be able to limit the spread of microorganisms that may be introduced into non-sterile products such as oral and topical medications during their manufacture and use. In sterile products (multiuse preparations), preservatives should kill all the microbial contaminants that might be introduced inadvertently during consumer use. It is essential that a preservative is not toxic in relation to the intended method of administration of the preserved preparation [2].

Biocides have been widely used in the control of bacteria for decades, and they are incorporated into various products including disinfectant formulations, preservatives, pesticides, cosmetics, and antiseptics [1]. A biocidal product should have the following features: (i) sufficiently effective with no undesirable effects on the target organisms (i.e., resistance or cross-resistance); (ii) no direct or indirect harmful consequences as a result of its remains on human or animal health; (iii) no improper environmental consequences itself, or as a result of its

\section{Springer Open}

(๑) The Author(s). 2020 Open Access This article is licensed under a Creative Commons Attribution 4.0 International License, which permits use, sharing, adaptation, distribution and reproduction in any medium or format, as long as you give appropriate credit to the original author(s) and the source, provide a link to the Creative Commons licence, and indicate if changes were made. The images or other third party material in this article are included in the article's Creative Commons licence, unless indicated otherwise in a credit line to the material. If material is not included in the article's Creative Commons licence and your intended use is not permitted by statutory regulation or exceeds the permitted use, you will need to obtain permission directly from the copyright holder. To view a copy of this licence, visit http://creativecommons.org/licenses/by/4.0/. 
remains (i.e., its fate and distribution throughout the environment; particularly contamination of surface waters, groundwater, and drinking water; its influence on nontarget organisms); (iv) its physical and chemical properties have been determined and considered acceptable for the purposes of the appropriate use, storage, and transport of the product [3].

\section{Main text}

Chemical groups and mode of action of different biocides Biocides are broad-spectrum in activity and they are often applied in numerous settings. They have multiple and non-specific target sites in the microorganisms constituting DNA, RNA, the cytoplasmic membrane, proteins, and the other cytosolic components. The interaction between a biocide and a microorganism follows a series of events as the biocide first binds to the cell surface of the microbe, and then penetrates its cell wall and membrane, arriving to the cytoplasm, where it can affect the cellular proteins or nucleic acids. The harmful action results from the cellular damage caused by the biocide at a certain stage during this process [4].

Unlike most antibiotics, limited numbers of biocides exert their action on one specific target within the cell of the microbe. Most of the biocides are capable of acting at numerous sites in the cell and the interaction leading to cell death is not always well known [5]. The site of the lethal action depends on the concentration utilized [6]. For example, the low concentration of triclosan inhibits a certain enzyme in the fatty acid biosynthesis, the enoyl-acyl carrier protein reductase, FabI [7]. Whereas at higher concentrations, triclosan has a membrane-disrupting action [8].

The action of biocides can be classified into low, intermediate, and high level. Low-level action of biocides includes inactivation of bacteria, fungi, and viruses (e.g., alcohols, idophores, diluted solution of sodium hypochlorite, quaternary ammonium compounds). The intermediate level action can affect more number of bacteria, fungi, and viruses, (e.g., concentrated solution of calcium hypochlorite and phenolic compounds). The high-level action can kill them not only deactivating them, so they are also named as chemical sterilizers (e.g., peroxides, highly concentrated hypochlorite solutions, and peracetic acids) [9].

An overview of the commonly used biocides of different chemical groups and their general field of application will be discussed as shown in Table 1 focusing on their use within the healthcare settings, food production, and animal husbandry. Also, the mode of action of each compound on bacteria will be described as shown in Fig. 1.

A. Alcohols:
In the group of alcohols, ethanol (EtOH) and isopropanol are the most frequently utilized compounds. The activity of alcohols is broad-spectrum and rapid; they are active against bacteria, viruses, and fungi; however, they can not affect spores. Alcohols are extensively used for hand, skin, and hard surface disinfection in healthcare settings. There is little knowledge about the specific mode of actions of alcohols; however, the primary mode of action is the denaturation and coagulation of proteins. This disturbs the membrane structure and function resulting in the release of the intracellular components, interference with cell metabolism and other cellular functions, and cell lysis. Due to a lack of the sporicidal activity, alcohols are not recommended to be used in sterilization. However, they are widely utilized for skin antisepsis and hard-surface disinfection. Lower concentrations could also be used as preservatives [1].

\section{B. Aldehydes:}

The main aldehydes used as biocides are formaldehyde (FH) (as monoaldehyde) and glutaraldehyde (as dialdehyde). They have a broad spectrum of action including bacteria, fungi, viruses, and bacterial spores. In healthcare settings, they are used for the disinfection of equipment like endoscopes. Formaldehyde is additionally utilized in veterinary hygiene. They can interact with proteins, DNA, and RNA by cross-linking of the free amino groups. They are used as sterilants, particularly for low-temperature disinfection and sterilization of surgical equipment [1].

\section{Chlorine and iodine compounds:}

This group comprises biguanides, chlorine releasing agents (e.g., sodium hypochlorite), and iodine releasing agents (iodophors). The antimicrobial action of chlorinereleasing agents is not well known. Nevertheless, due to their strong oxidizing potential, these compounds are supposed to react with proteins and enzymes causing disturbance of the cytoplasmic membrane and interfering with the cell metabolism. Sodium hypochlorite solutions are commonly utilized for hard-surface disinfection (household bleach) [10]. Iodine in water solutions has been commonly used for antiseptic purposes for many years; however, they have been exchanged by the iodophors, because of the tissue irritation and excessive staining adverse effects of iodine. The most commonly used iodophor is povidone-iodine that is utilized as an antiseptic and disinfectant. Iodine is bactericidal, virucidal, fungicidal, and sporicidal. The effect of iodine is rapid and is assumed to interact with proteins and enzymes (especially the thiol groups), nucleotides, and fatty acids; however, the exact mechanism of action is not well understood [10]. 
Table 1 Uses and chemical structures of the commonly used biocides

\begin{tabular}{|c|c|c|}
\hline Biocide type & Chemical structure* & Use \\
\hline Alcohols & 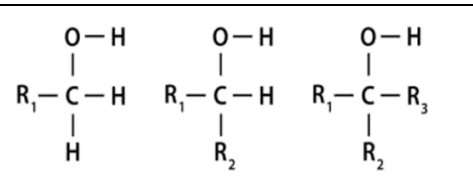 & $\begin{array}{l}\text { Antisepsis } \\
\text { Disinfection } \\
\text { Preservation }\end{array}$ \\
\hline Aldehydes & & Chemosterilization \\
\hline $\begin{array}{l}\text { Chlorine and iodine } \\
\text { compounds }\end{array}$ & $\begin{array}{l}\mathrm{HOCL}, \mathrm{CL}_{2} \\
\text { Povidone iodine }\end{array}$ & $\begin{array}{l}\text { Antisepsis } \\
\text { Disinfection } \\
\text { Preservation }\end{array}$ \\
\hline Peroxygen compounds & $\mathrm{H}_{2} \mathrm{O}_{2}$ & $\begin{array}{l}\text { Antisepsis } \\
\text { Disinfection } \\
\text { Preservation }\end{array}$ \\
\hline Phenols an bisphenols & Bisphenol & $\begin{array}{l}\text { Disinfection } \\
\text { Preservation }\end{array}$ \\
\hline $\begin{array}{l}\text { Quaternary ammonium } \\
\text { compounds }\end{array}$ & $R^{3}-\frac{R^{2}}{R^{2}} R^{4}$ & $\begin{array}{l}\text { Disinfection } \\
\text { Preservation }\end{array}$ \\
\hline Bases and acids & $\begin{array}{l}\mathrm{NaOH}, \mathrm{Na}_{2} \mathrm{CO}_{3},(\mathrm{KOH}),\left(\mathrm{Ca}(\mathrm{OH})_{2}\right) \\
\mathrm{H}_{2} \mathrm{SO}_{4}, \mathrm{HCL}\end{array}$ & Disinfection \\
\hline
\end{tabular}

* R: alkyl group.

*R: alkyl group

Chlorhexidine belongs to the biguanides (divalent cationic compound). Chlorhexidine constitutes one of the most frequently used biocides in antiseptic products, particularly in handwashing and oral products, in addition, it is used as a disinfectant and preservative.
The mechanism of action of chlorhexidine on bacteria has been well investigated and its lethal impact comprises a series of events. This includes an attraction of the cationic compound to the negatively charged bacterial cell, then uptake of the compound which attacks the 


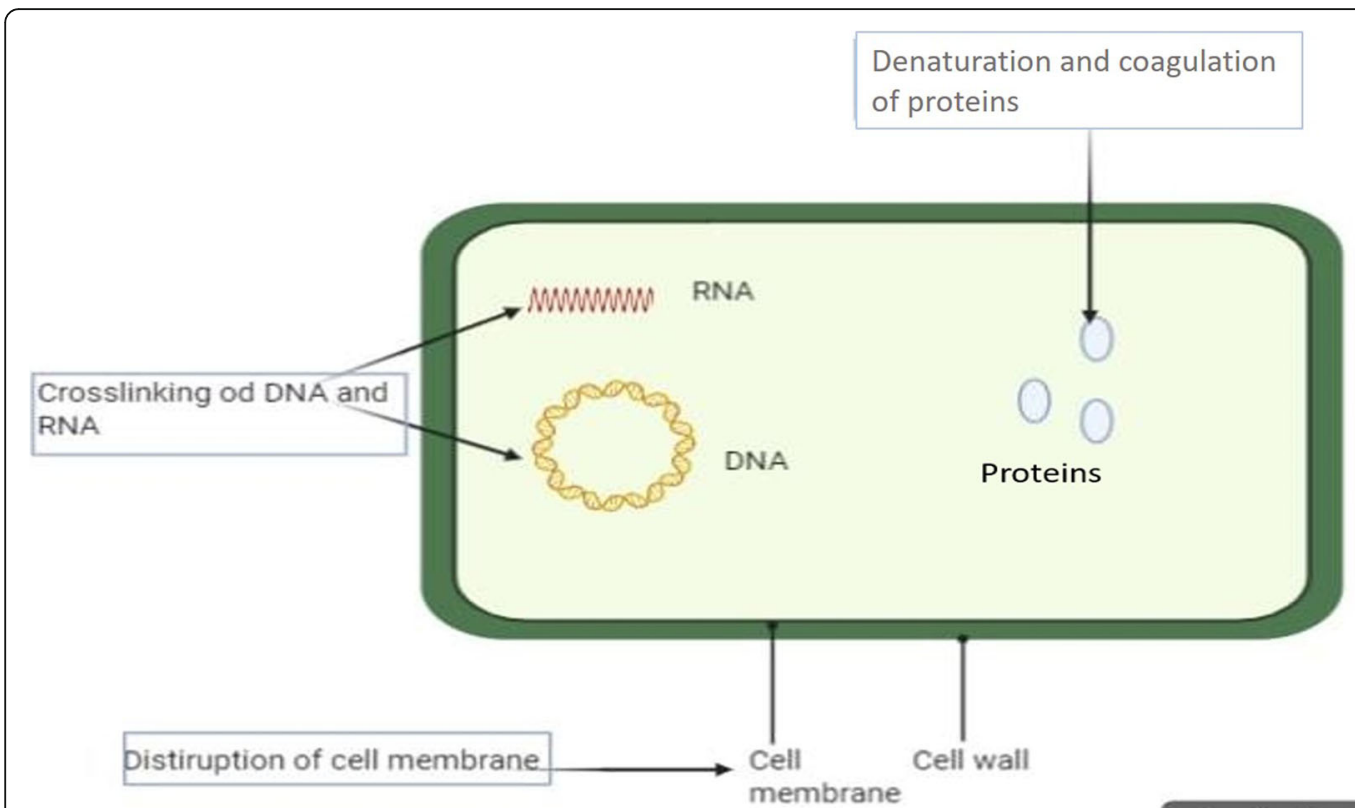

Fig. 1 The main targets of the commonly used biocides

cytoplasmic membrane causing inhibition of the membrane-bound enzymes and leakage of intracellular constituents. Chlorhexidine causes precipitation of cytoplasm at high concentrations [11].

\section{Peroxygen compounds:}

Hydrogen peroxide (HP) is the most important compound that belongs to this group. HP is a strong oxidizing agent with a broad spectrum of activity against bacteria, viruses, yeast, and bacterial spores. It is broadly utilized for disinfection, antisepsis, and sterilization. It is a colorless liquid which is commercially available in various concentrations that range from 3 to $90 \%$. HP attacks cells by the formation of free hydroxyl radicals $(\cdot \mathrm{OH})$ that are highly reactive molecules due to their strong oxidizing action. They can react with the important cellular components such as membrane lipids, proteins, ribosomes, enzymes, and DNA leading to their destruction [12].

\section{E. Phenols and bis-phenols:}

Phenolic compounds have a broad spectrum of activity against bacteria, fungi, and viruses. They have been utilized as antiseptics, disinfectants, and preservatives. Triclosan (TCS) is the most important bisphenol compound that is commonly utilized in antiseptic soaps and hand rinses. TCS is also widely used in the industry and is incorporated in various products including toys, deodorants, toothpaste, and cosmetics. The mechanism of action of phenols and bisphenols is believed to be the disturbance of the cytoplasmic membrane leading to a rapid release of the intracellular components. Though, TCS has a specific target, the enoyl-ACP reductase in bacteria, encoded by the $f a b$ I gene, which is involved in fatty acid synthesis $[13,14]$.

\section{F. Quaternary ammonium compounds (QACs):}

Benzalkonium chloride (BAC) and cetrimide are the main agents within the group of QACs which are active against bacteria, enveloped viruses and fungi. They are commonly utilized for disinfection of areas where animals are kept and transported (e.g., floors, walls, and transportation vehicles). They are also used for the disinfection of food handling regions [15].

Cytoplasmic membrane is the main target for QACs. The mechanism of action of these compounds is supposed to follow series of events; adsorption to the cell wall and diffusion through it, then interaction with and disruption of the cytoplasmic membrane causing the release of cellular components and precipitation of cellular contents and death [15].

\section{G. Bases and acids:}

Caustic soda $(\mathrm{NaOH})$, soda $\left(\mathrm{Na}_{2} \mathrm{CO}_{3}\right)$, caustic potash $(\mathrm{KOH})$, and hydrated lime $\left(\mathrm{Ca}(\mathrm{OH})_{2}\right)$ have antimicrobial action against some bacteria and viruses. Caustic soda and caustic potash have been commonly used for cleaning of surfaces [1]. 
Acids are either mineral or organic acids. The most vital mineral acids are sulphuric acid $\left(\mathrm{H}_{2} \mathrm{SO}_{4}\right)$ and hydrochloric acid $(\mathrm{HCl})$ that are commonly used in the food processing industry for cleaning of the different surfaces. Organic acids (e.g., lactic, acetic, and citric acids) are frequently used as preservatives. Acids are thought to have their antimicrobial action by $\mathrm{pH}-$ mediated coagulation of proteins [1].

\section{Factors influencing the choice of biocides}

Choice of the most suitable biocide for a certain purpose depends on some factors which are summarized as follow:

A. Properties of the chemical compound:

The process of killing or inhibiting the growth of microorganisms by any antimicrobial agent is a chemical reaction. The rate and the extent of this reaction will be affected by the concentration and the formulation of the chemical compound, temperature, and $\mathrm{pH}$. Tissue toxicity determines whether the chemical agent can be utilized as antiseptic or preservative, and this limits the numbers of agents used for these applications or necessitates the usage of much lower concentrations of this agent [16].

B. Microbiological challenge: The level of microbial contamination (the bioburden) and the type of microorganisms present have an important effect on the result of the treatment. If the bioburden is high, higher concentrations of the antimicrobial and/or long exposure times may be needed.

Microorganisms are different in their sensitivity to the action of the chemical compounds [16].

C. Intended application: The intended application of the antimicrobial agent (preservation, antisepsis, or disinfection) will affect its choice and influence its performance [16].

D. Toxicity of the antimicrobial compound [16].

\section{Factors affecting the efficacy of biocides}

The efficacy of a disinfection process is a result of the right application of an efficient biocide. There are some causes that might lead to loss of the efficacy of biocides and they are summarized as follows [17]:

A. The use of an effective product (i.e., a biocide having an incomplete spectrum of activity). So, all the microorganisms which are outside the range of the product efficiency will survive and ultimately develop resistance to the specific antimicrobial agent and to related or unrelated agents (crossresistance) [18].
B. Application of the product without regard to the correct conditions recommended by the supplier. This includes concentration, $\mathrm{pH}$, temperature, time of application, and inactivation by organic matter [18].

C. The extended application of biocides at sub-lethal concentrations may lead to the adaptation of microorganisms to the biocide [18].

D. Insufficient contact between the biocide and the microorganisms.

E. Insufficient availability of the biocide [18].

All these situations may decrease the expected action of biocides [18]. Nevertheless, the main reasons for the failure of the disinfection process are linked mainly to the development of microbial resistance. Gilbert and McBain [18] defined resistance as a relative insusceptibility of a microorganism to a certain treatment under a certain set of conditions. For biocides, it is generally quantified as the concentration that leads to sub-lethal effects on the bacterial cells. In addition to the environmental factors, resistance to biocides can be intrinsic (natural property of a microorganism) or acquired (by mutation or acquisition of plasmids or transposons) [19].

\section{Mechanism of resistance to biocides}

Unlike antibiotics, target sites for biocides are not very specific and hence their resistance mechanisms are not specific as well. The resistance mechanisms of bacterial isolates to biocides are either intrinsic (inherent resistance of bacteria to biocides which can be achieved through reduced uptake or physiological adaptation or enzymatic degradation) [20] or acquired by mutations in the genetic material of bacteria (alteration of the preexisting genes) or uptake of new genetic material (mobile genetic elements like plasmids) by horizontal gene transfer [21-23].

\section{A. Intrinsic resistance:}

Intrinsic resistance may be as a result of the reduced uptake of the biocides either due to the presence of a permeability barrier or efflux pumps. Permeability barrier can limit the penetration of the biocides and thus, reducing its efficacy. Gram-negative bacteria (for example) are generally less susceptible to antimicrobials than Gram-positive bacteria. This is due to the presence of the outer membrane in Gram-negative bacteria, as it can act as a permeability barrier leading to a reduction in the uptake of biocides [24, 25]. Multidrug efflux pumps are common in bacteria. There are five main classes of efflux pump systems and they are as follow: 
- The major facilitator (MF) superfamily

- The ATP-binding cassette (ABC) family

- The small multidrug resistance (SMR) family

- The resistance-nodulation-division (RND) family

- The multidrug and toxic compound extrusion (MATE) family [26].

In addition, the physiological condition of bacteria can influence their sensitivity to biocides. Biofilms, for example, represent a serious problem as bacterial cells present within biofilms have been found to be less susceptible to biocides $[27,28]$. Numerous mechanisms can explain this decline in the susceptibility: penetration of the biocidal compound into the biofilm may be limited, possible chemical interaction between the antimicrobial molecules and the biofilm matrix thus, reduce the efficacy of the biocide, and the formation of microenvironments which are both nutrient- and oxygen-deficient leading to an exhibition of stress response rendering bacteria less susceptible to biocides after adaptation to these microenvironments [17, 29].

Enzymatic transformation or inactivation of the biocides into non-toxic forms has been described in some bacteria [30]. For example, aerobic microorganisms have enzymatic systems which relieve the bacteria from the toxic byproducts (like production of hydrogen peroxide and superoxide throughout the oxidative respiration); superoxide dismutase enzyme gets rid of the superoxide from the cell and catalase enzyme eliminates the hydrogen peroxide [31].

\section{B. Acquired resistance:}

Bacteria can acquire resistance to different antimicrobials by:

i) target site alteration

ii) impermeability

iii) enzymatic modification or degradation

iv) active efflux

Since the antimicrobial agents in general have a specific target site in bacteria, the acquisition of one or more of these mechanisms can render the bacteria resistant to multiple antimicrobials [32].

\section{Agents with the potential for co-selection of resistance}

\section{A. Antibiotics:}

Antibiotics display a high antimicrobial potency and a selective toxicity that is satisfactory in many cases to allow their usage as anti-infective agents in the body tissues. This is attributed to their high specific action on the microbial target [33], which acts with the host's immune system to resolve the microbial colonization or infection over an extended period of time [20]. Reduced susceptibility of bacteria to an antibiotic may be innate (for example due to characters of the microbe's cell envelope, energy metabolism, or the presence of another metabolic pathway) [34]. On the other side, the reduced susceptibility may be acquired through single- or multistep mutation that has an impact on the target site and/ or the effective concentration of the antibiotic in the cell, or by the gaining of genetic material encoding certain feature like an alternative to the target molecule or an inactivating enzyme [35]. Bacterial resistance may be stimulated by sub-therapeutic antibiotic concentrations in certain tissues or organs and the ability of antibiotics to induce non-specific mutagenesis in bacteria [36]. An important parameter of the antibioticmicrobe combination is the minimum inhibitory concentration (MIC), which is the lowest concentration of antibiotic which can inhibit the growth of the microbe and it is likely to be therapeutically effective if achieved in the target tissue [37].

\section{B. Biocides:}

Contrary to antibiotics, biocides have more diverse applications, do not work with the benefit of a simultaneous immune response, and commonly have to deal with microbes in protected or resistant states (for instance, in biofilms or organic matter, in moisture- or nutrient-limited environments, or after sporulation). Consequently, they are intended to be lethal, usually after a single application, and usually have multiple biochemical and structural targets to achieve a great destructive effect on the microorganisms [38].

The "in use" concentrations of biocides are laboratory determined by minimum lethal concentrations which are intended to be rapidly lethal to the target microorganisms [18]. Many biocides when applied at their inuse concentrations seem to affect multiple targets, with the membrane effects being a mutual target [38].

\section{Mechanisms linking altered susceptibilities of bacteria to antibiotics and biocides}

On initial concern, differences between antibiotics and biocides in respect to their targets and their modes and intensity of action, would propose that there is not likely to be much mutual ground between the two types of compounds. Indeed, antibiotic effects on bacteria can be significantly reduced by only single-step mutations in the target enzymes, or by the production of inactivating enzymes like $\beta$-lactamases [35, 39].

Clinical doses are cautiously controlled to avoid toxicity or other harmful impacts. Thus, such specific, 
single-step alterations can result in clinical resistance to antibiotics. Similar mechanisms are seen infrequently in case of biocides like mutation and upregulation of $f a b \mathrm{I}$ gene in relation to TCS [40-42] and are considered to have little impact in "real world" applications where numerous targets are affected by biocides simultaneously $[43,44]$. However, there are some phenomena that cause reduced susceptibility both to biocides and to antibiotics and which are either intrinsic in the microorganisms or are acquired by mutation or genetic transfer under suitable conditions as discussed before [45, 46].

In terminology to precisely describe the linked changes in susceptibility among antimicrobial agents (co-selection), there is an important difference between crossresistance and co-resistance [47] as shown in Fig. 2. Associations arising as a result of physiological adaptations that have effects on the action of a number of compounds are called cross-resistance. Examples include efflux pump over-expression or upregulation [48], reduced permeability of the cell envelope, or (commonly in relation to antibiotics) alteration in a target site or production of an inactivating enzyme (such as an extendedspectrum $\beta$-lactamase) that inhibits the action of compounds from more than one class [37]. On the other hand, when the mechanisms of reduced susceptibility are different but are genetically linked, the phenomenon is termed co-resistance. There is also another common definition of cross-resistance, i.e., resistance to related agents for example members of the same antibiotic family $[49,50]$.

\section{Effects on bacterial fitness}

Adaptation of bacterial cells to biocides frequently comes with some related costs to them. This is mainly significant when the change is mutationally leading to the constitutive expression of certain resistance mechanisms [18]. In the present situation, the broad substrate efflux pumps is a very good example as they consume some cell energy and indiscriminately remove some beneficial metabolic materials from the microbial cell $[43,51]$. A further example is plasmids that encode resistance to both antibiotics and biocides, where instability and the fitness cost need a selective pressure for their preservation $[52,53]$.

There is an immediate indication of the bacterial fitness costs in the laboratory, in terms of decreased size of colonies or other growth properties [53], or the cost may be only observed in the communities where there is a competition within and between different microbial species. However, co-selection is not often costly and prolonged exposure to biocides may select compensatory adaptations which could restore the bacterial fitness [17, 54]. Moreover, certain resistance adaptations, such as enhancement of biofilm formation, may improve the bacterial survival in other environments [55].

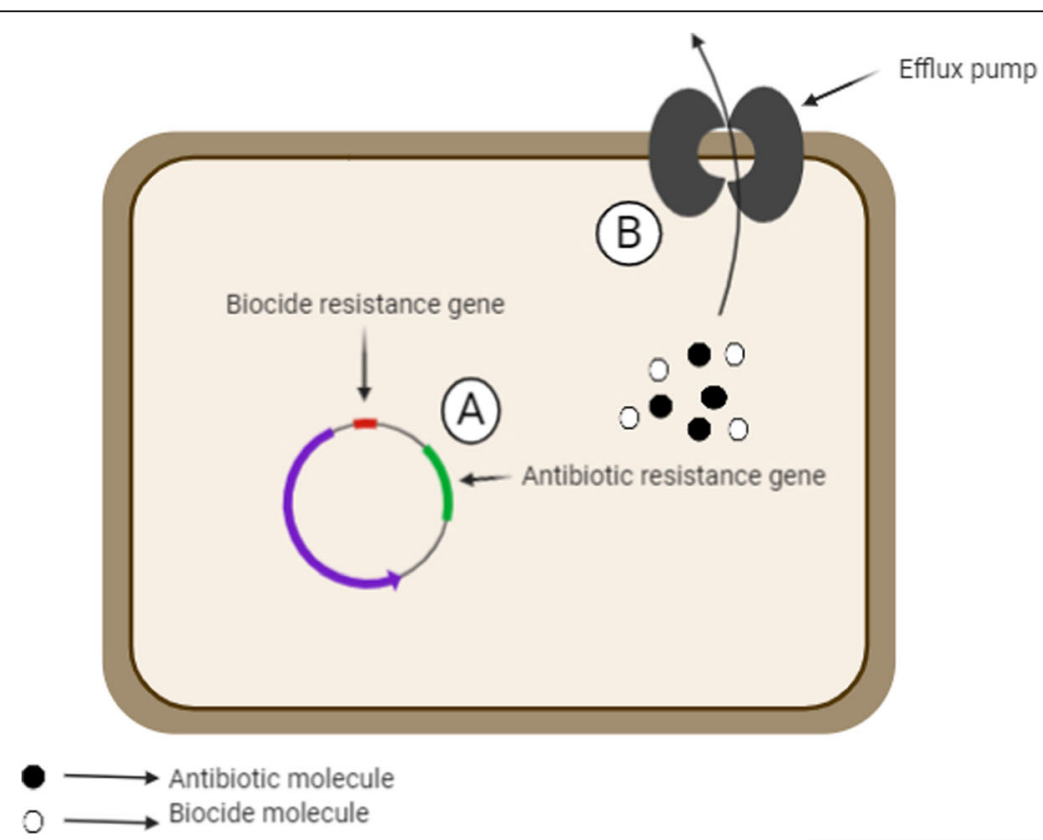

Created in BioRender.com bio

Fig. 2 Co-selection in bacteria. A: Co-resistance where the genes of resistance to antibiotics and biocides are physically located on the same mobile genetic element. B: Cross-resistance where a single gene encoding a resistance mechanism (e.g., efflux pumps) confer resistance to both biocides and antibiotics 


\section{Future perspectives}

A. The future of biocides in the healthcare environment:

Undoubtedly, biocides will remain to have a significant role in the prevention and control of different infections in the healthcare sector, although some caution is necessary in relation to their use and the type of the products which should contain antimicrobials. For the purposes of disinfection and antisepsis, chemical biocides are often utilized at relatively high concentrations (i.e., above their bacterial MICs many times) to achieve a rapid kill. At these concentrations, a biocide will affect multiple target sites within the bacteria [16], and the development of resistance is therefore improbable.

The increased usage of biocides in products and formulations is undoubtedly driven by the demand to control and decrease the spread of the hospital-associated infections (HAIs) [56]. But the use of these products needs to be balanced between the benefit of controlling the spread of infections and the probable risk associated with its use, not only in terms of developing microbial resistance but also their toxicity and environmental contamination [1].

In this regard, the benefits of using biocides on noncritical surfaces to avoid the transmission of HAIs should be further evaluated [57]. Evaluation of the role of biocides in the governing of nosocomial infections is hard to be assessed in situ, although this information is vital for the selection of suitable regimens [16]. For a biocidal formulation to be effective, good knowledge of the chemical biocide, training of the end-users, and good compliance are very necessary. It has to be well-known that, when applicable, physical processing, (e.g., heat sterilization), provides many advantages over the chemical disinfection and it should be the method of choice when it is possible [16].

A good understanding of the mechanisms of action of biocides, the factors affecting their action, and the different problems that are associated with the specific practice is essential and could have a role in the improvement of the biocidal product, in terms of activity and usage. For example, improved compliance to hand hygiene in the healthcare environments was observed with the introduction of different hand rub products [58].

There are some interesting developments in the use of biocides in the prevention of many potential infections. In the medical field, the utilization of biocide combinations in catheters and implants, and other medical devices is an advancing field of research, though medical devices that contain biocides may be of some concern [16]. In the dental field, light-activated biocides are under study to be used in the treatment of root canals
[59]. There is no doubt that the advances in the biocidal research will contribute to the development of new biocidal products or biocide containing medical devices with particular usage and improved efficacy [16].

\section{B. Phytochemicals:}

Antimicrobial resistance is more significant when bacterial cells are present in a biofilm [60]. Therefore, new biocides are essential for effective disinfection and antisepsis. Phytochemicals (secondary metabolites from plants) are considered an unexploited source of new biocides [61, 62]. Plants can synthesize a very large number of organic compounds that can be classified as primary and secondary metabolites. Primary metabolites (like sugars, fatty acids, amino acids, and nucleic acids) are compounds that have important roles in photosynthesis, growth and development, and respiration [63].

Secondary metabolites (or phytochemicals) are those chemicals which are required for the interactions of plants with the environment, like pathogen and pest defense compounds, Ultraviolet-B sunscreens, and allopathic agents. They are structurally diverse and many are found in a limited number of species in the plant kingdom [63].

Plant products have been used since early times as flavors in beverages and foods, and also for medical purposes in order to prevent and cure different diseases with varying degrees of success. A small percentage of plant species has been explored phytochemically till date; and there is a great possibility for the determination of new bioactive compounds [64]. Plants are important sources for natural bioactive compounds like secondary metabolites as they adsorb sunlight to do photosynthesis and these produce secondary metabolites [65].

The antimicrobial activity of plant extracts has been largely attributed to the secondary metabolites (phytochemicals), which are synthesized to protect the plant against different external stress conditions such as microbial infections [66].

Several phytochemicals are proven to be effective, with low cytotoxicity, degradable and affordable, environmentally friendly, against microorganisms makes them a vital source for antimicrobial agents and, consequently, remarkably alternative to the commonly used biocides [67]. Additionally, they have the advantage that they do not exhibit the side effects which are often associated with the use of the synthetic chemicals and this is a significant benefit of using these plant-derived antimicrobials $[68,69]$. Secondary metabolites can be classified according to their chemical structures, which also affect their antimicrobial characters, and it was found that the major groups responsible for antimicrobial activity from plants include phenolics, alkaloids, and terpenoids which 
are widely found in non-flowering medicinal plants. For example, the fern, Aspleniumnidus nidus contained quercetin-7-O-rutinoside and gliricidin 7-Ohexoside which can fight against 3 pathogenic bacteria: Proteus mirabilis, Proteus vulgaris, and Pseudomonas aeruginosa [70].

\section{Conclusion}

The aim of this study was to analyze the influence of the step-wise exposure and adaptation of bacterial isolates to biocides. The vast and extensive use of biocides in order to control microbial growth has considerable environmental and economic effects. The misuse of biocides establishes an extra risk to public health as it can lead to the selection of pathogens that are not susceptible to the available antimicrobials.

\section{Abbreviations}

ABC: ATP-binding cassette; BAC: Benzalkonium chloride; EtOH: Ethyl alcohol; FH: Formaldehyde; HAls: Hospital-associated infections; HP: Hydrogen peroxide; MF: Major facilitator; MIC: Minimum inhibitory concentration; MATE: Multidrug and toxic compound extrusion; QACs: Quaternary ammonium compounds; RND: Resistance-nodulation-division; SMR: Small multidrug resistance; TCS: Triclosan

\section{Authors' contributions}

FS and TE conceptualized the project and gave technical inputs in preparing the manuscript. AA and EE prepared the manuscript. All authors have read and approved the manuscript.

\section{Availability of data and materials}

All data and materials are available upon request.

Ethics approval and consent to participate

Not applicable.

\section{Consent for publication}

Not applicable.

\section{Competing interests}

No competing interests to declare.

Received: 13 May 2020 Accepted: 22 September 2020

Published online: 21 November 2020

\section{References}

1. McDonnell G, Russell AD (1999) Antiseptics and disinfectants: activity, action, and resistance. Clin Microbiol Rev 12(1):147-179

2. Mugoyela V, Mwambete KD (2010) Microbial contamination of nonsterile pharmaceuticals in public hospital settings. Therap Clin risk Manag 6:443-448

3. Knapp L, Amézquita A, McClure P, Stewart S, Maillard JY (2015) Development of a protocol for predicting bacterial resistance to microbicides. Appl Environ Microbial 81(8):2652-2659

4. Armentano I, Arciola CR, Fortunati E, Ferrari D, Mattioli S, Amoroso M, Rizzo J, Kenny JM, Visai L (2014) The interaction of bacteria with engineered nanostructured polymeric materials: a review. Sci World J 10:410-423

5. Davies J, Davies D (2010) Origins and evolution of antibiotic resistance. Microbiol Mol Biol Rev 74(3):417-433

6. Russell $A D, M c D o n n e l l ~ G(2000)$ Concentration: a major factor in studying biocidal action. J Hosp Infect 44:1-3

7. Payne DJ, Miller WH, Berry V, Brosky J, Burgess WJ, Chen E, Jr W, Fosberry A, Greenwood R, Heerding D, Moore T, Pearson S, Salyers K, Seefeld M, Smyth M, Takata D, Vaidya K, Yuan C, Huffman W (2002) Discovery of a novel and potent class of Fabl-directed antibacterial agents. Antimicrob Agents Chemother 46: 3118-3124
8. Villalain J, Mateo CR, Aranda FJ, Shapiro S, Micol V (2001) Membranotropic effects of the antibacterial agent triclosan. Arch Biochem Biophys 390:128-136

9. Eadaoin MJ, Timothy JM (2008) Sonication used as a biocide a review: Ultrasound a greener alternative to chemical biocides. Chim Oggi 26:22-24

10. Chundamala J, Wright JG (2007) The efficacy and risks of using povidoneiodine irrigation to prevent surgical site infection: an evidence-based review. Can J Surg 50(6):473-481

11. Saleem EG, Seers CA, Sabri AN, Reynolds EC (2016) Dental plaque bacteria with reduced susceptibility to chlorhexidine are multidrug resistant. BMC Microbiol 16(214):220

12. Vatansever F, de Melo WC, Avci P, Vecchio D, Sadasivam M, Gupta A (2013) Antimicrobial strategies centered around reactive oxygen species, bactericidal antibiotics, photodynamic therapy, and beyond. FEMS Microbiol Rev 37(6):955-989

13. Galal AM (2006) Natural product-based phenolic and non-phenolic antimicrobial food preservatives and 1,2,3,4-tetrahydroxybenzene as a highly effective representative: a review of patent literature 2000-2005. Recent Pat Antiinfect Drug Discov 1(2):231-239

14. Saleh S, Haddadin RN, Baillie S, Collier PJ (2010) Triclosan-an update. Lett Appl Microbiol 52:87-95

15. Carmona-Ribeiro AM, Carrasco LD (2013) Cationic antimicrobial polymers and their assemblies. Int J Mol Sci 14:9906-9946

16. Millard JV (2005) Antimicrobial biocides in the healthcare environment: efficacy, usage, policies, and perceived problems. Ther Clin Risk Manag 1(4): 307-320

17. Russell AD (2004) Bacterial adaptation and resistance to antiseptics, disinfectants and preservatives is not a new phenomenon. J Hosp Infect 57(2):97-104

18. Gilbert P, McBain AJ (2003) Potential impact of increased use of biocides in consumer products on prevalence of antibiotic resistance. Clin Microbiol Rev 16:189-208

19. Davin-Regli A, Pagès JM (2012) Cross-resistance between biocides and antimicrobials: an emerging question. Rev sci tech Off int Epiz 31(1):89-104

20. Cerf O, Carpentier B, Sanders P (2010) Tests for determining in-use concentrations of antibiotics and disinfectants are based on entirely different concepts: "resistance" has different meanings. Int J Food Microbiol 136(3):247-254

21. Culyba MJ, Mo CY, Kohli RM (2015) Targets for combating the evolution of acquired antibiotic resistance. Biochem 54:3573-3582

22. Hall CW, Mah TF (2017) Molecular mechanisms of biofilm-based antibiotic resistance and tolerance in pathogenic bacteria. FEMS Microbiol Rev 41(3): 276-301

23. Tumah HN (2009) Bacterial biocide resistance. J Chemother 21:5-15

24. Russell AD (2003) Similarities and differences in the responses of microorganisms to biocides. J Antimicrob Chemother 52:750-763

25. Winder CL, Al-Adham IS, Abdel Malek SM, Buultjens TJ, Horrocks AJ, Collier PJ (2001) Outer membrane protein shifts in biocide-resistant Pseudomonas aeruginosa PAO1. Appl Microbiol 89:289-295

26. Poole K (2005) Efflux-mediated antimicrobial resistance. J Antimicrob Chemother 56:20-51

27. Seiler C, Berendonk TU (2012) Heavy metal driven co-selection of antibiotic resistance in soil and water bodies impacted by agriculture and aquaculture. Front Microbiol 3:17-24

28. Sonbol F, El-Banna T, Abd El-Aziz A, El-Ekhnawy E (2018) Biological characters of vancomycin resistant Staphylococcus aureus isolates from a university hospital in Egypt. Arch Clin Microbial 9:72-81

29. Bridier $A$, Briandet $R$, Thomas V, Dubois-Brissonnet $F$ (2011) Resistance of bacterial biofilms to disinfectants: a review. Biofouling 27:1017-1032

30. Cloete TE (2003) Resistance mechanisms of bacteria to antimicrobial compounds. Int Biodeterior Biodegradation 51:277-282

31. Demple B (1996) Redox signaling and gene control in the Escherichia coli soxRS oxidative stress regulon-a review. Gene 179:53-57

32. van Hoek AH, Mevius D, Guerra B, Mullany P, Roberts AP, Aarts HJ (2011) Acquired antibiotic resistance genes: an overview. Front Microbiol 2:203-220

33. Chopra I, Hesse L, O'Neill AJ (2002) Exploiting current understanding of antibiotic action for discovery of new drugs. J Appl Microbiol 92:4-15

34. Elbanna T, Abdelaziz A, Sonbol S, Elekhnawy E (2019) Adaptation of Pseudomonas aeruginosa clinical isolates to benzalkonium chloride retards its growth and enhances biofilm production. Mol Biol Rep 46:3437-3443

35. Poole K (2002) Mechanisms of bacterial biocide and antibiotic resistance. J Appl Microbiol 92:55-64 
36. Cogliani C, Goossens H, Greko C (2011) Restricting antimicrobial use in food animals: Lessons from Europe. Microbe 6:274-279

37. Wales A, Davies R (2015) Co-selection of resistance to antibiotics, biocides and heavy metals, and its relevance to foodborne pathogens. Antibiotics 4 : 567-604

38. Morente EO, Fernandez-Fuentes MA, Burgos MJG, Abriouel H, Pulido RP Galvez A (2013) Biocide tolerance in bacteria. Int J Food Microbiol 162:13-25

39. Levy S (2002) Active efflux, a common mechanism for biocide and antibiotic resistance. J Appl Microbiol 92:65S-71S

40. Li B, Webster TJ (2002) Bacteria antibiotic resistance: New challenges and opportunities for implant-associated orthopedic infections. J. Orthop. Res. 36(1), 22-32 Maillard JY. Bacterial target sites for biocide action. J Appl Microbiol 92:16-27

41. Nikaido H (2009) Multidrug resistance in bacteria. Annu Rev Biochem 78 : 119-146

42. Rensch U, Klein G, Kehrenberg C (2013) Analysis of triclosan-elected Salmonella enterica mutants of eight serovars revealed increased aminoglycoside susceptibility and reduced growth rates. PLOS ONE 8:10-22

43. Bloomfield SF (2002) Significance of biocide usage and antimicrobial resistance in domiciliary environments. J Appl Microbiol 92:144-157

44. Schweizer H (2001) Triclosan: a widely used biocide and its link to antibiotics. FEMS Microbiol Lett 202(1):1-7

45. Vijayakumar R, Sandle T (2019) A review on biocide reduced susceptibility due to plasmid-borne antiseptic-resistant genes-special notes on pharmaceutical environmental isolates. J Appl Microbiol 126(4):1011-1022

46. Elbanna T, Sonbol F, Abd El Aziz A, Elekhnawy E (2018) Prevalence and antimicrobial susceptibility of vancomycin resistant staphylococci in an Egyptian university hospital. J Med Microb Diagn 7:1-8

47. Buffet-Bataillon S, Tattevin P, Bonnaure-Mallet M, Jolivet-Gougeon A (2012) Emergence of resistance to antibacterial agents: The role of quaternary ammonium compounds-a critical review. Int J Antimicrob Agents 39:381-389

48. Abdel Malek SM, Badran YR (2010) Pseudomonas aeruginosa PAO1 adapted to 2-phenoxyethanol shows cross-resistance to dissimilar biocides and increased susceptibility to antibiotics. Folia Microbiol 55:588-592

49. Chang H, Cohen T, Grad Y, Hanage W, O'Brien T, Lipsitch M (2015) Origin and proliferation of multiple-drug resistance in bacterial pathogens. Microbiol Mol Biol Rev 79(10):101-116

50. Munita JM, Arias CA (2016) Mechanisms of Antibiotic Resistance. Microbiol Spect 4(2):10-22

51. Sonbol S, Elbanna T, Abdelaziz A, Elekhnawy E (2018) Impact of triclosan adaptation on membrane properties, efflux and antimicrobial resistance of Escherichia coli clinical isolates. J Appl Microbiol 126(3):730-739

52. Subbiah M, Top EM, Shah DH, Call DR (2011) Selection pressure required for long-term persistence of blaCMY-2-positive IncA/C plasmids. Appl Environ Microbiol 77(13):4486-4493

53. Gullberg E, Albrecht LM, Karlsson C, Sandegren L, Andersson DI (2014) Selection of a multidrug resistance plasmid by sub lethal levels of antibiotics and heavy metals. MBIO. 5:10-25

54. Abdelaziz A, Sonbol S, Elbanna T, Elekhnawy E (2018) Exposure to sublethal concentrations of benzalkonium chloride induces antimicrobial resistance and cellular changes in Klebsiellae pneumoniae clinical isolates. Microb Drug Resist 25(5):631-638

55. Sheridan A, Lenahan M, Condell O, Bonilla-Santiago R, Sergeant K, Renaut J, Duffy G, Fanning S, Nally JE, Burgess CM (2013) Proteomic and phenotypic analysis of verocytotoxigenic Escherichia coli (VTEC) with tolerance to triclosan. J Proteome 80:78-90

56. Favero MS (2002) Products containing biocides: perceptions and realities. Appl Microbiol 92:72-77

57. Bloomfield S, Beumer R, Exner M, Far G, Scott E, Nat K (2004) Disinfection and the prevention of infectious disease. Am J Infect Control 32:311-312

58. Boyce JM, Pittet D (2002) Guidelines for hand hygiene in health-care settings. Am J Infect Control 30:41-46

59. Wilson M (2004) Lethal photosensitization of oral bacteria and its potential application in the photodynamic therapy of oral infections. Photocop Photobio Sci 3:412-418

60. Capita R, Vicente-Velasc M, Rodríguez-Melcón C, García-Fernández C, Carballo J, Alonso-Calleja C (2019) Effect of low doses of biocides on the antimicrobial resistance and the biofilms of Cronobacter sakazakii and Yersinia enterocolitica. Sci Rep 9:15905
61. Borges A, Abreu AC, Dias C, Saavedra MJ, Borges F, Simões M (2016) New perspectives on the use of phytochemicals as an emergent strategy to control bacterial infections including biofilms. Mol 21(7):877-889

62. Borges A, Saavedra MJ, Simões M (2015) Insights on antimicrobial resistance, biofilms and the use of phytochemicals as new antimicrobial agents. Curr Med Chem 22(21):2590-2614

63. Kliebenstein DJ, Osbourn A (2012) Making new molecules-evolution of pathways for novel metabolites in plants. Curr Opin Plant Biol 15(4):415-423

64. Negi PS (2012) Plant extracts for the control of bacterial growth: efficacy, stability and safety issues for food application. Int J Food Microbiol 156(1):7-17

65. Ghasemzadeh A, Ghasemzadeh N (2011) Flavonoids and phenolic acids: Role and biochemical activity in plants and human. J Med Plant Res 5(31): 6697-6703

66. Barbieria R, Coppoa E, Marcheseb A, Dagliac M, Sobarzo-Sánchezde E, Nabavi S (2017) Phytochemicals for human disease: an update on plantderived compounds antibacterial activity. Microbiol Res 196:44-68

67. Upadhyay A, Upadhyaya I, Kollanoor-Johny A, Venkitanarayanan K (2014) Combating pathogenic microorganisms using plant-derived antimicrobials: a minireview of the mechanistic basis. Bio Med Res Intern 2014:1-18

68. Cheesman MJ, llanko A, Blonk B, Cock IE (2017) Developing new antimicrobial therapies: are synergistic combinations of plant extracts/ compounds with conventional antibiotics the solution? Pharm Rev 11(22): $57-72$

69. Hintz T, Matthews KK, Di R (2015) The use of plant antimicrobial compounds for food preservation. Bio Med Res Inter 2015:246-264

70. Gyawali R, Ibrahim SA (2014) Natural products as antimicrobial agents. Food Control 46:412-429

\section{Publisher's Note}

Springer Nature remains neutral with regard to jurisdictional claims in published maps and institutional affiliations.

\section{Submit your manuscript to a SpringerOpen ${ }^{\circ}$ journal and benefit from:}

- Convenient online submission

- Rigorous peer review

- Open access: articles freely available online

High visibility within the field

- Retaining the copyright to your article

Submit your next manuscript at $>$ springeropen.com 